\title{
STUDY OF COMBUSTION IN DI DIESEL ENGINE FOR DIFFERENT COMPRESSION RATIOS USING EXPERIMENTAL AND CFD
}

\section{APPROACH}

\author{
Patil Pradip kailas ${ }^{1}$, Wagh Hemant $K^{2}$, Patil Vijayendra Maharu ${ }^{3}$, Kumbhar Anil $\mathbf{H}^{\mathbf{4}}$ \\ ${ }^{I}$ PG Student, R.C.Patel Institute of Technology, Shirpur, Maharashtra, India \\ ${ }^{2}$ Assistant Professor, R.C.Patel Institute of Technology, Shirpur, Maharashtra, India \\ ${ }^{3} P G$ Student, TIT, Bhopal, MP, India \\ ${ }^{4} P G$ Student, TIT, Bhopal, MP, India
}

\begin{abstract}
The developments are being carried out continuously in the field of brake specific fuel consumption and brake thermal efficiency, combustion parameters and emission of gases with diesel as a fuel.etc. Along with the many mechanisms are used for achieving the variable compression ratio, dual piston mechanism, multi link mechanism, varying the stroke length of the connecting rod, eccentric movement of crankshaft. This paper includes the different compression ratios (12.5-18) to find the optimum value and the numerical data are validated with experimental data.
\end{abstract}

Keywords: DI Diesel Engine, Performance, Combustion, Emission, Compression Ratio, Modeling. $* * *$

\section{INTRODUCTION}

Improving internal combustion (IC) engine efficiency is a prime concern today. A lot of engineering research has gone into the improvement of the thermal efficiency of the (IC) engines, so as to get more work from the same amount of fuel burnt and the energy present in the combustion chamber only a portion gets converted in to useful output power. Most of the energy produced by these engines is wasted as heat. In addition to friction losses and losses to the exhaust, there are other operating performance parameters that affect the thermal efficiency. These include the fuel lower calorific value, compression ratio, and ratio of specific heats [6]. Compression ratio is the ratio of the total volume of the combustion chamber when the piston is at the bottom dead centre to the total volume of the combustion chamber when piston is at the top dead center. Theoretically, increasing the compression ratio of an engine can improve the thermal efficiency of the engine by producing more power output [8]. There are many mechanisms are used for achieving the variable compression ratio. Dual piston mechanism, multi link mechanism, varying the stroke length of the connecting rod, Eccentric movement of crankshaft. The most widely used method of varying the compression ratio is the Tilting Cylinder arrangement where the cylinder head is tilted to an angle thereby increasing the clearance volume. Different angle of tilt correspond to different compression ratios. It was found that performance parameters viz.BSFC, BTHE are better at higher compression ratios. Performance study done on the Diesel engine by varying the engine design parameters such as the compression ratio shows that, as the compression ratio is increases the brake thermal efficiency and the brake power rises. Brake specific Fuel consumption is reduced at higher compression ratios [9]

\section{CASE DESCRIPTION}

Variable Compression Ratio (VCR) engine is used for the current study. The engine is a four stroke (DI) direct injection, single cylinder diesel engine. The engine specification and parameters are shown in table - 1. [10]. It consists of a centrally located fuel injector and single inlet and exhaust valve. A commercial CFD code ANSYS Fluent is used for combustion analysis. A $3 \mathrm{D}$ model with a centrally located fuel injector is created with a $30^{\circ}$ sector as shown in fig 2 . The complete model of engine with inlet and exhaust valves is shown in fig 2.

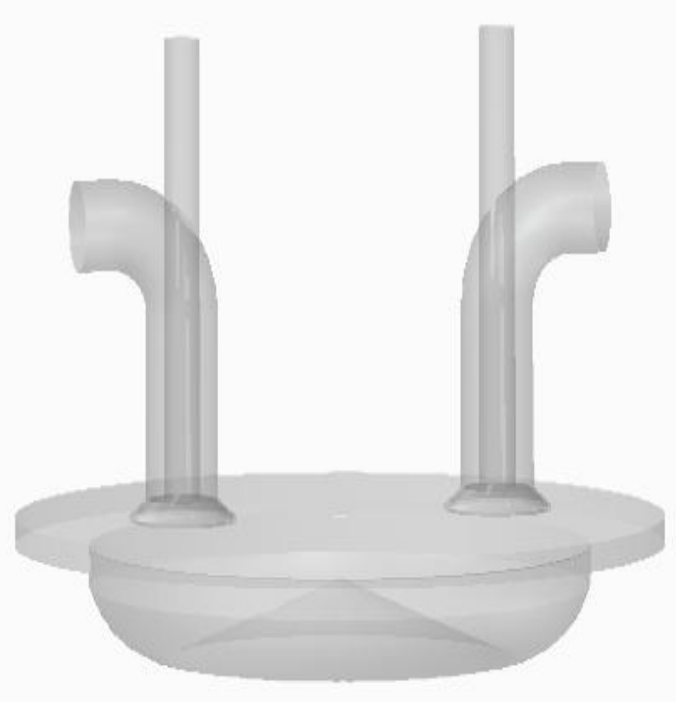

Fig - 1: model of Engine. 


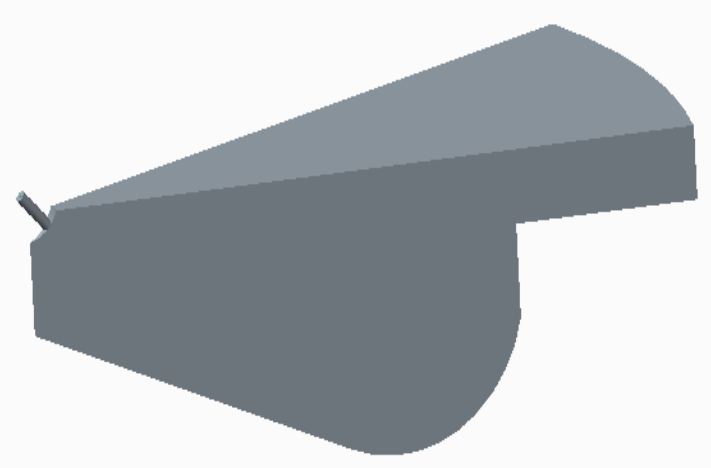

Fig - 2: A $30^{\circ}$ sector model for analysis.

Various fluid zones and interfaces are provided for different regions of a model to enhance the results and for providing accurate interactions of boundary conditions. A dynamic mesh is carried out to simulate the suction and compression process up to the point of injection. After injection the monitors are applied for getting results of combustion parameters such as pressure, temperature and volume. The Experimental analysis will be carried out for three different compression ratios CR 12.5, CR 15 and CR 18. Pressure, volume and temperature will be found out for the three compression ratios. In numerical analysis same results will be calculated using CFD code and finally the experimental results will be compared with CFD results.

Table-1: Engine specifications.

\begin{tabular}{|l|l|}
\hline Parameter & Value \\
\hline Cylinder Bore & $87.5 \mathrm{~mm}$ \\
\hline Connecting rod Length & $234 \mathrm{~mm}$ \\
\hline Stroke & $110 \mathrm{~mm}$ \\
\hline Engine Speed & $1538 \mathrm{rpm}$ \\
\hline Compression Ratio & 17.5 \\
\hline Inlet Valve open before TDC & $4.5^{\circ}$ \\
\hline Inlet Valve close after BDC & $36.5^{\circ}$ \\
\hline Fuel injection start before TDC & $23^{\circ}$ \\
\hline Exhaust Valve open before BDC & $35.5^{\circ}$ \\
\hline Exhaust Valve close after TDC & $4.5^{\circ}$ \\
\hline
\end{tabular}

\section{EXPRIMENTAL ANALYSIS}

As explained earlier, three compression ratios are considered for experimental analysis CR 12.5, CR 15 and CR 18. The combustion Performance is funded for these CR. The experimental setup is shown in fig 3. The setup consists of single cylinder, four stroke, VCR (Variable Compression Ratio) Diesel engine connected to eddy current type dynamometer for loading. The compression ratio can be changed without stopping the engine and without altering the combustion chamber geometry by specially designed tilting cylinder block arrangement. Setup is provided with necessary instruments for combustion pressure and crankangle measurements. These signals are interfaced to computer through engine indicator for $\mathrm{P} \theta-\mathrm{PV}$ diagrams. Provision is also made for interfacing airflow, fuel flow, temperatures and load measurement. The set up has standalone panel box consisting of air box, two fuel tanks for duel fuel test, manometer, fuel measuring unit, transmitters for air and fuel flow measurements, process indicator and engine indicator. Rota meters are provided for cooling water and calorimeter water flow measurement [10]. The engine is run ideal for 10 to 15 minutes the readings and graphs for various combustion parameters such as pressure, volume and temperature vs. Crank angle are obtained using a program Engine Soft which is an integrated part of the setup. Thus, several readings are taken for CR 12.5, CR 15 and CR 18 for no load conditions and the study is carried out for different compression ratios.

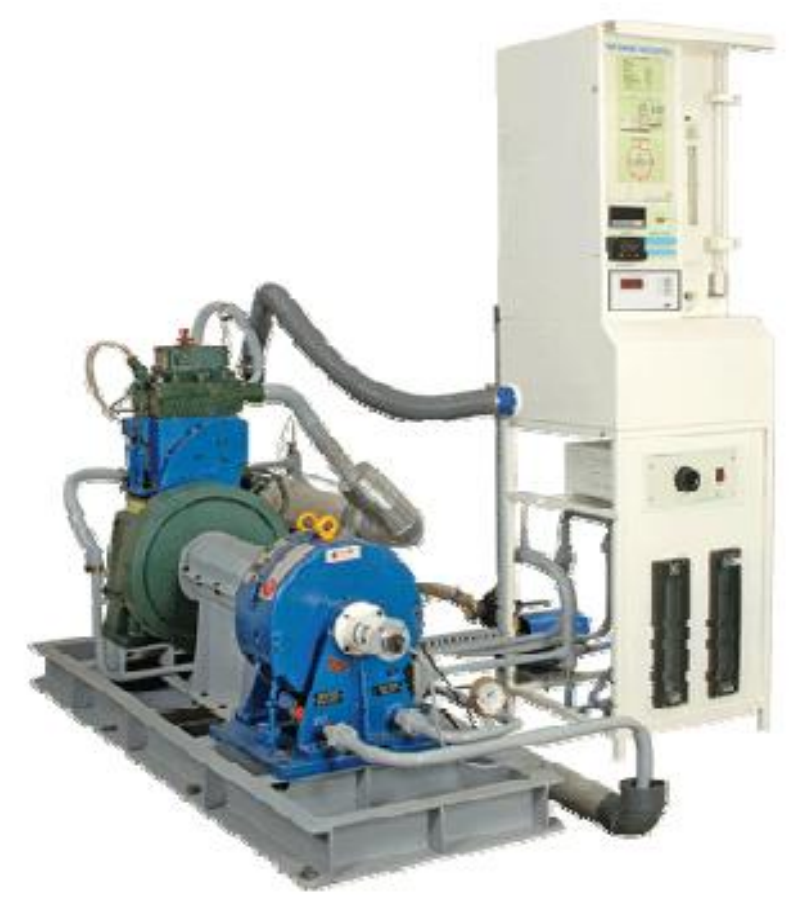

Fig - 3: Experimental Setup.

\section{NUMERICAL MODELING}

The combustion simulation of DI diesel engine was developed using Fluent software and the various equations of the multi-dimensional model were solved by the software automatically..Inlet condition is given at atmospheric pressure and temperature. During piston motion the layers above the piston will increase when the piston move from top dead centre to bottom dead centre and the layers will decrease when piston move from bottom dead centre to top dead centre. The simulation is conducted under the transient condition. From this simulation, we can find the variation in parameters like pressure, volume, temperature etc. We also defined species transport model, in that model we can define type of combustion model (Non-premixed combustion), chemistry and boundary condition. The engine parameters are mention in the dynamic mesh setting box like crank shaft speed (rpm), starting crank angle (deg), crank period (deg), crank angle step size (deg), piston stroke $(\mathrm{mm})$, and connecting rod length $(\mathrm{mm})$. The pressurevelocity coupling is achieved by using PISO (Pressure Implicit Splitting of Operators) Algorithm. The second order upwind is used for momentum and the First order upwind is 
used for density, turbulent kinetic energy, and transient equations.

\section{RESULTS AND DISUCSSIONS}

The CFD code Ansys Fluent was used for solving the combustion analysis the simulation was carried from CA 317 to CA 390 . From table 1 it is seen that the fuel injection starts at $337^{\circ} \mathrm{CA}$ hence, to study the effect of combustion accurately the simulation time is defined form $317^{\circ}$ to $390^{\circ}$. The simulation starts at $20^{\circ}$ before fuel injection and ends at $53^{\circ}$ after fuel injection. The monitors were studied for simulation giving values of pressure, volume and temperature at each crank angle. Simulations have been carried out for different compression ratios CR 12.5, CR 15 and CR 18. The graphs for pressure vs. CA, volume vs. CA and Temperature vs. CA are plotted for the output of numerical simulation. Finally, the graphs obtained from Experimental study are compared with the Numerical CFD study and both are compared for study. The various graphs comparison for experimental and CFD study and contour plots are shown in fig 4 to fig 15 .

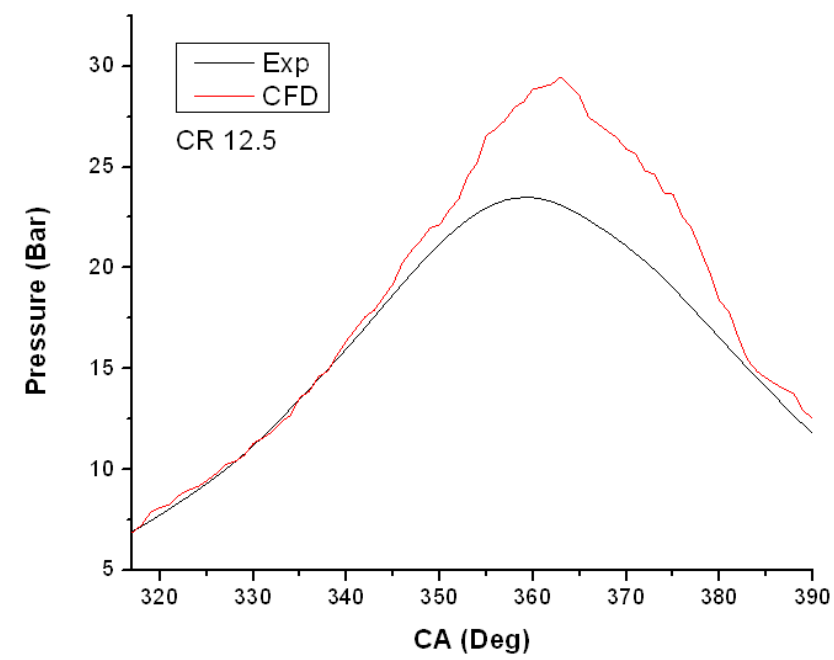

Fig - 4: Experimental and CFD Pressure at CR 12.5

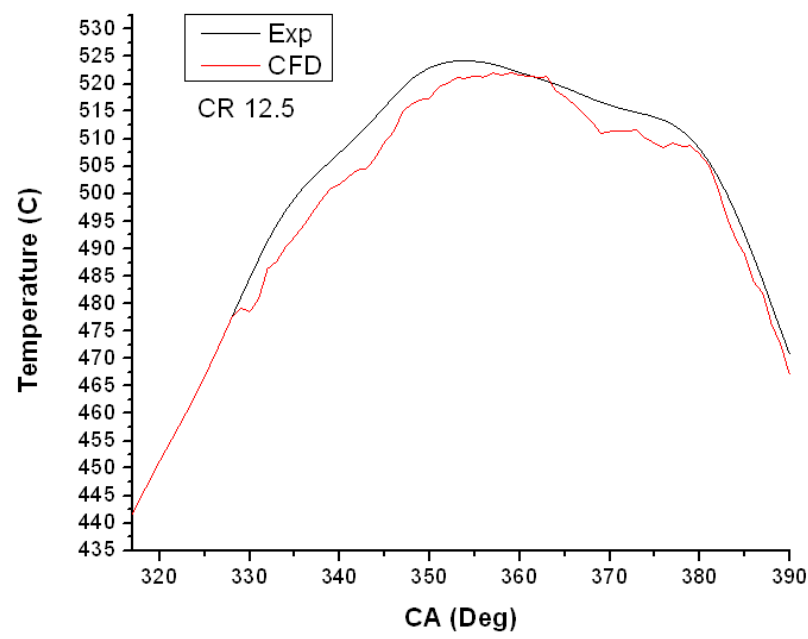

Fig - 5: Experimental and CFD Temperature at CR 12.5

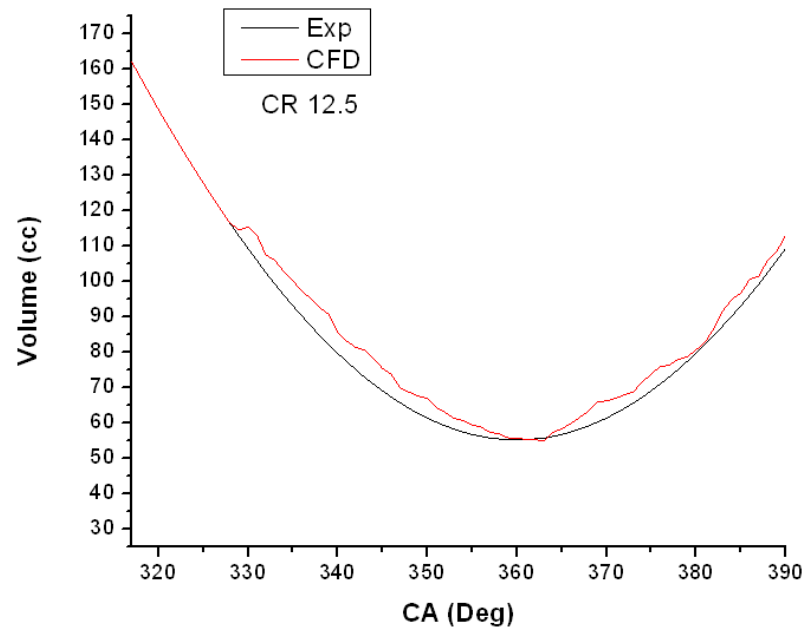

Fig - 6: Experimental and CFD Volume at CR 12.5

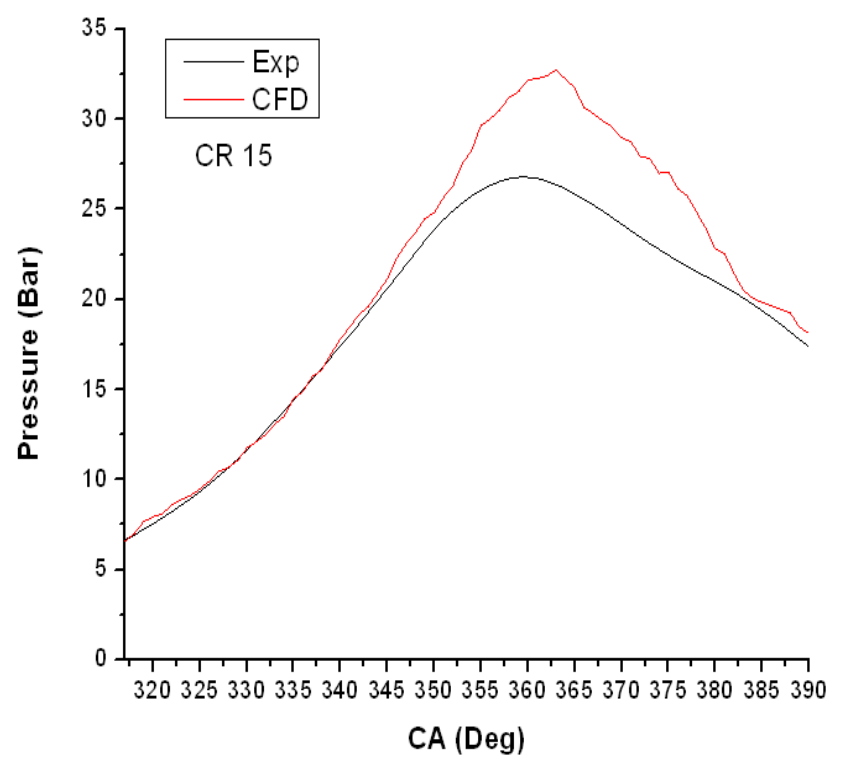

Fig - 7: Experimental and CFD Pressure at CR 15

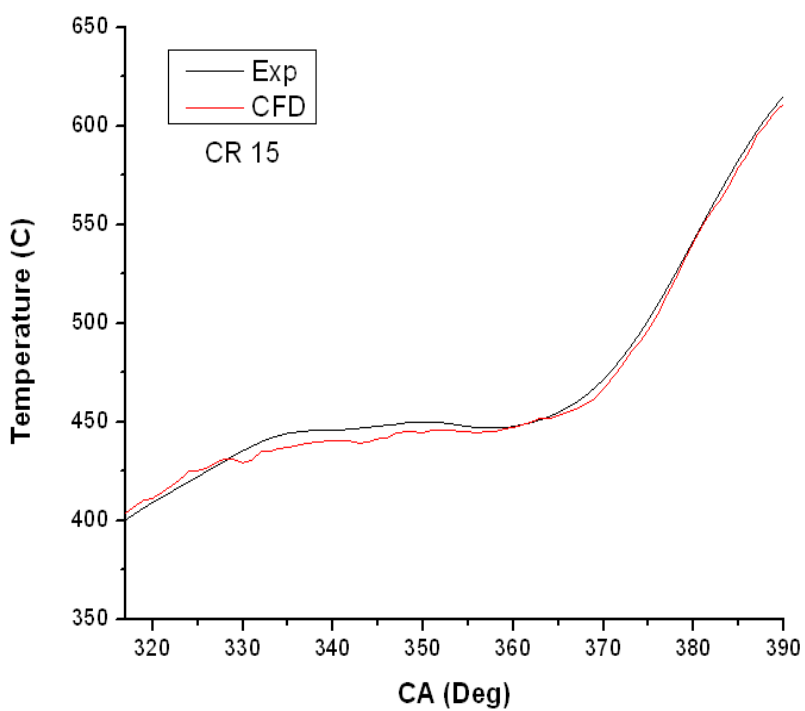

Fig - 8: Experimental and CFD Temperature at CR 15 


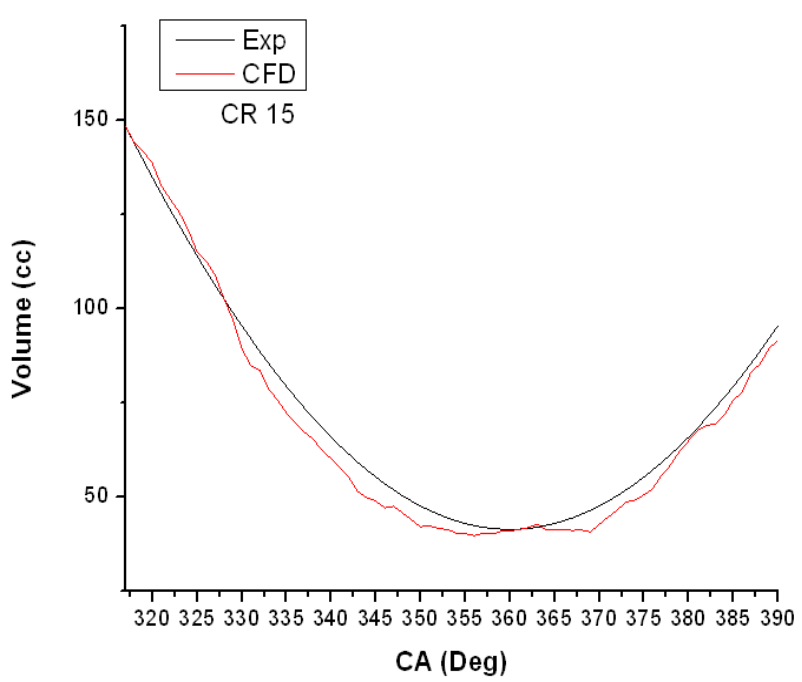

Fig - 9: Experimental and CFD Volume at CR 15

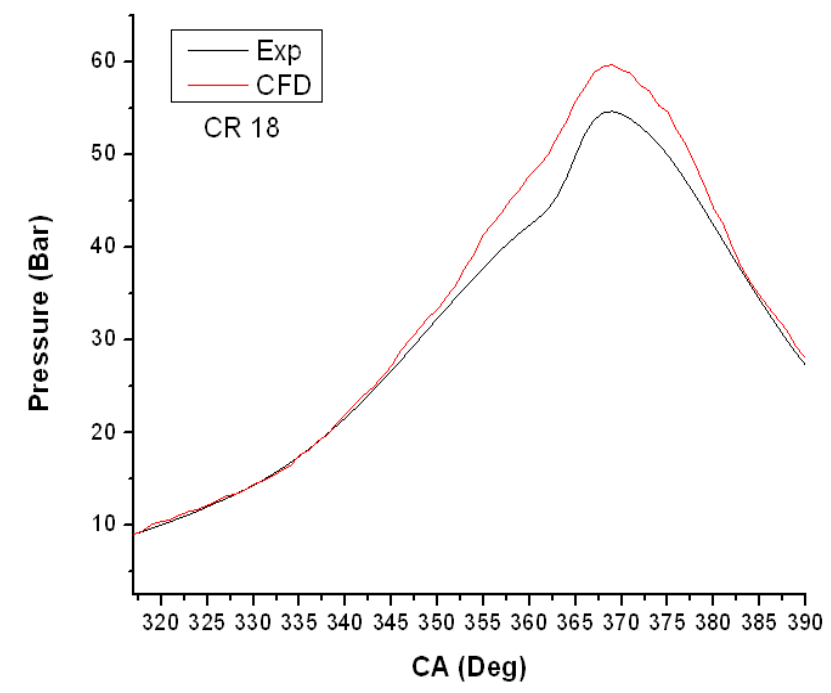

Fig - 10: Experimental and CFD Pressure at CR 18

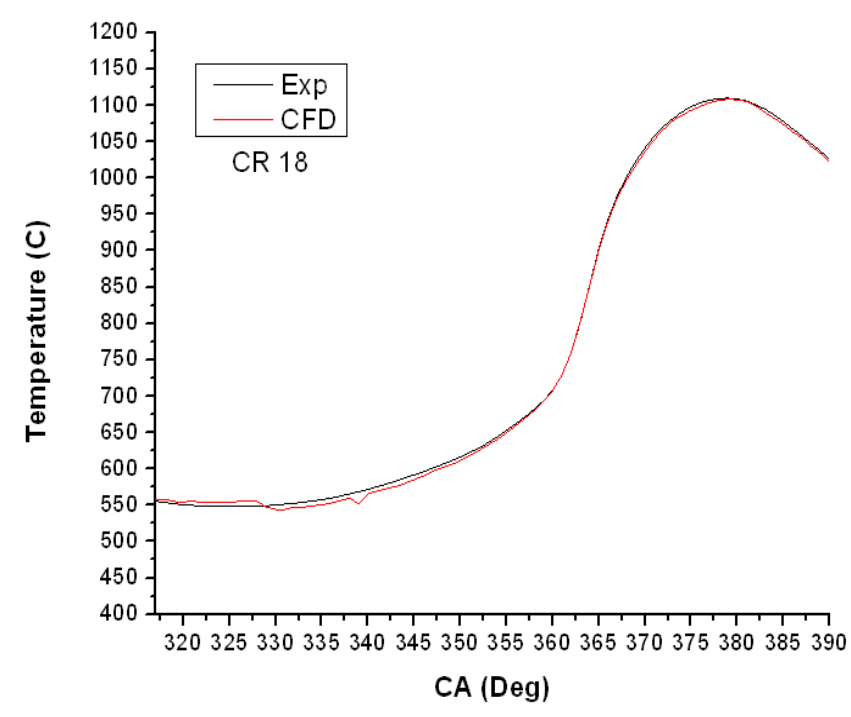

Fig - 11: Experimental and CFD Temperature at CR 18

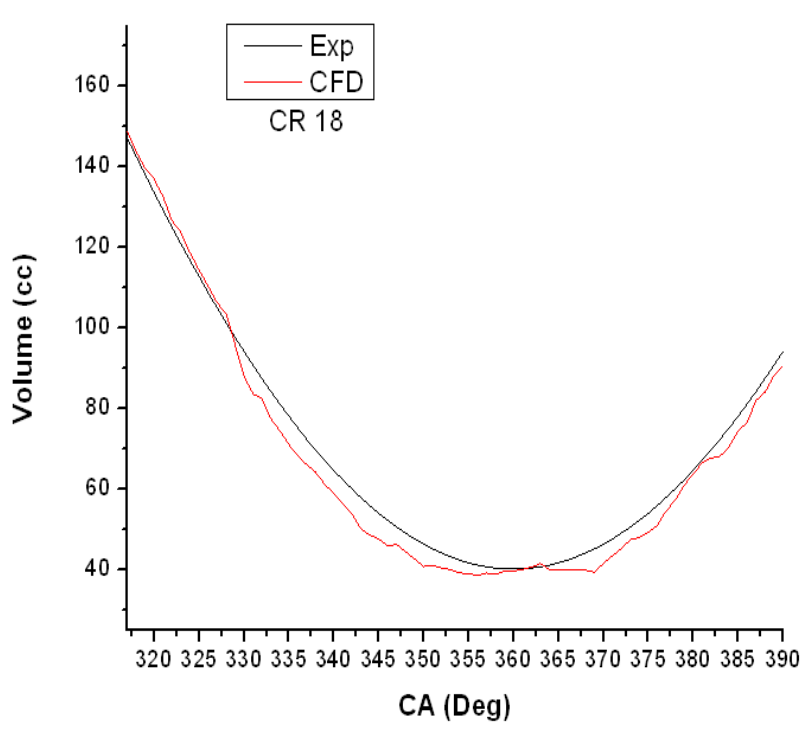

Fig - 12: Experimental and CFD Volume at CR 18

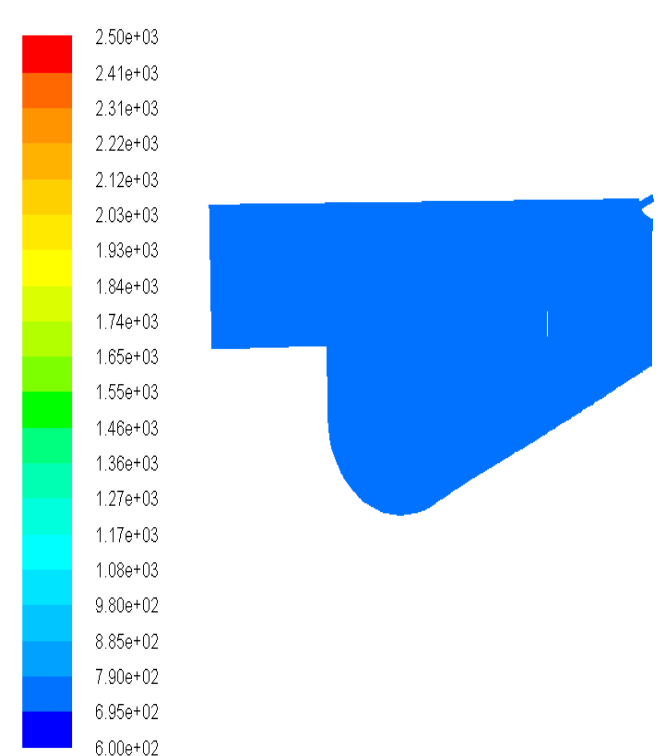

Fig - 13: Temperature at $327^{\circ} \mathrm{CA}$. and CR 18

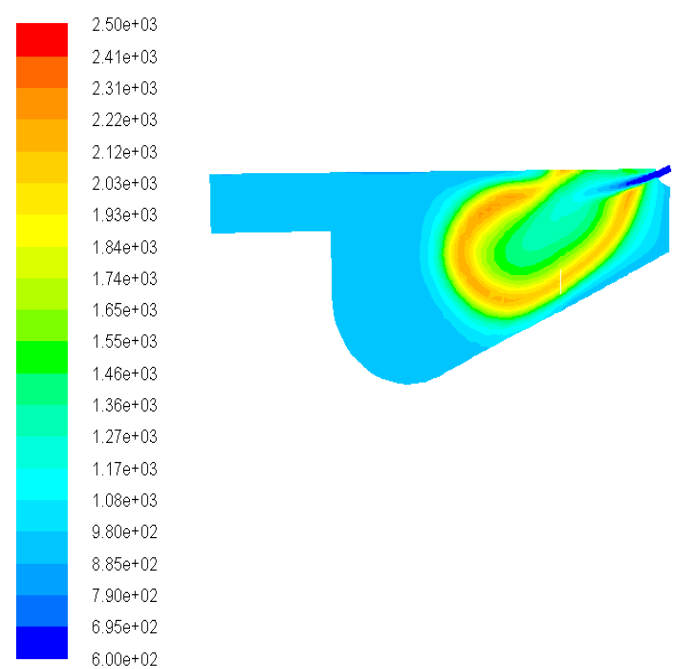

Fig - 14: Temperature at $342^{\circ} \mathrm{CA}$ and $\mathrm{CR}$ at 18 


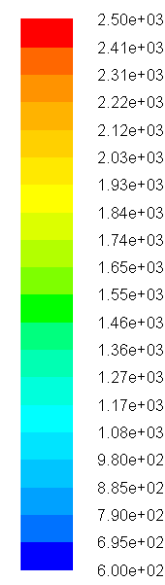

Fig - 15: Temperature at $387^{\circ} \mathrm{CA}$ and CR 18.

\section{CONCLUSIONS}

The model was created using Gambit and combustion parameter was analyzed using Ansys Fluent. The results show values of pressure, temperature and volume comparable to experimental values. Hence the developed model is suitable for predicting the combustion parameters of a compressed ignition engine. By changing the compression ratio the pressure, temperature and volume can be varied and it is used for find out optimum compression ratio.

\section{REFERENCES}

[1]. F. Payri , J. Benajes, X. Margot , A. Gil, "CFD modeling of the in-cylinder flow in direct-injection Diesel Engines." Computers \& Fluids 33 (2004) 995-1021.

[2]. S GavudhamaKarunanidhi, Melvinraj C R, Sarath Das K P, G Subba Rao,"CFD Studies of Combustion in Diesel Engine.'International Journal of Engineering Research and Applications (IJERA),ISSN: 2248-9622,Vol. 3, Issue 4, JulAug 2013, pp.827-830.

[3]. S.M.Iameel Basha,P.IssacPrasad and K.Rajagopal,"Simulation of In-Cylinder processes in a DI Diesel Engine with Various Injection Timings" ARPN Journal of Engineering abd Applied Sxiences, Vol, 4, NO:1, Feb 2004. ISSN 1819 - 6608.

[4]. A.Hatziapostolou, G.Raptis, "CFD Modeling if InCylinder flow in a Variable Compression Spark-Ignited Engine"Proc. of the 9th WSEAS Int. Conf. on Mathematical and Computational Methods in Science and Engineering, Trinidad and Tobago, November 5-7, 2007.

[5]. Shahrir Abdullah, Wendy HardyonoKurniawan and AzhariShamsudeen, "Numerical Analysis of the Combustion Process in aCompressed Natural Gas Direct Injection Engine",Journal of Applied Fluid Mechanics, Vol. 1, No. 2, pp. 65-86, 2008.ISSN 1735-3645.

[6]. Wendy HardyonoKurniawan, Sharir Abdulla and AzhariShamsudeen, "A Computational Fluid Dynamics Study of Cold Flow Analysis For Mixture Preperation In a Motored Four-Stroke Direct Injection Engine"Journal of Applied Sciences 7 (19) : 2710-2724,2007. ISSN 18125654.

[7]. T.Morauszki, P.Mandli,Z.Horvath and M.R.Dreyer,"Simulation of Fluid Flow, Combustion and
Heat Transfer Processes In Internal Combustion Engines"Hungarian Journal of Industrial Chemistry Veszprem.Vol. 39 (1) pp.27-30 (2011).

[8]. V.Ganesan, "Internal Combustion Engines." Second edition, Tata Mcgraw Hill. ISBN 0-07-049457-6.

[9]. ANSYS Fluent User Manual.

[10]. Apex Innovations, VCR Engine User Manual. 